\title{
Regional coronary endothelial function is related to local coronary wall thickness in CAD patients using $3 \mathrm{~T} \mathrm{MRI}$
}

\author{
Allison G Hays ${ }^{1 *}$, Sebastian Kelle², Glenn A Hirsch', Jing Yu', Harsh K Agarwal', Gary Gerstenblith, \\ Matthias Stuber ${ }^{3}$, Robert G Weiss ${ }^{1}$
}

From 2011 SCMR/Euro CMR Joint Scientific Sessions

Nice, France. 3-6 February 2011

\section{Background}

Coronary endothelial function (endoFx) is an important physiologic indicator of vascular function. Abnormal function is present in patients with established coronary disease (CAD) and was recently shown to relate to the severity of luminal stenosis. ${ }^{1}$ However, luminal stenosis occurs late in the process of atherosclerosis, and a the extent to which abnormal coronary endoFx occurs early in atherosclerosis and whether it is related to measures of early, non-stenotic atherosclerosis, such as coronary wall thickness (CWT) are not known. Recent advances in MRI now allow non-invasive assessment of both anatomic (CWT) ${ }^{2-4}$ and functional (endoFx) vascular properties that in the past required invasive studies, precluding evaluation of healthy subjects and low risk populations.

\section{Objective}

To test the hypothesis that local endothelial dependent coronary vasoreactivity is inversely related to coronary wall thickness as measured using MRI.

\section{Methods}

Fourteen arteries in eleven healthy adults and fourteen arteries in eleven CAD patients with $<30 \%$ stenosis by recent coronary $\mathrm{x}$-ray angiography were studied with 3T MRI. To measure endoFx, spiral coronary MRI was performed before and during isometric hand-grip exercise, an endothelial-dependent stressor, and coronary cross-sectional area (CSA) change was measured as previously reported. ${ }^{1}$ For coronary vessel wall imaging,

JJohns Hopkins, Baltimore, MD, USA

Full list of author information is available at the end of the article black-blood dual-inversion spiral imaging was used to quantify CWT and normalized wall index (NWI=lumen area/total area).

\section{Results}

The stress-induced change in CSA was significantly higher in healthy adults $(15.2 \% \pm 11.0 \%$, mean \pm SD) than in those with mild, non-stenotic CAD $(-2.3 \% \pm 7.4 \%$, $\mathrm{p}<0.0001)$. Mean CWT was smaller in healthy subjects $(0.86 \pm 0.16 \mathrm{~mm})$ than in CAD patients $(1.49 \pm 0.31 \mathrm{~mm}$, $\mathrm{p}<0.0001)$. In contrast to healthy subjects, coronary

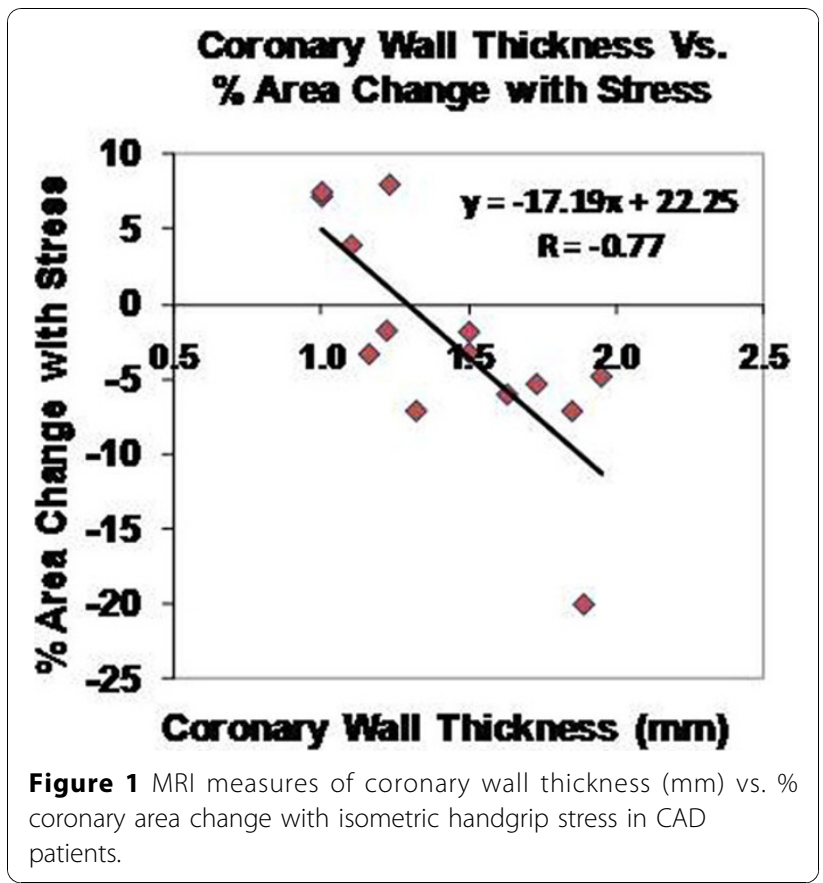

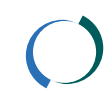

๑ 2011 Hays et al; licensee BioMed Central Ltd. This is an open access article distributed under the terms of the Creative Commons Attribution License (http://creativecommons.org/licenses/by/2.0), which permits unrestricted use, distribution, and reproduction in any medium, provided the original work is properly cited. 
endoFx correlated inversely with wall thickness in mild CAD patients (\%CSA vs CWT, $\mathrm{r}=-0.77, \mathrm{p}<0.001$ (Fig 1) and \%CSA vs. NWI, $\mathrm{r}=-0.70, \mathrm{p}=0.005)$.

\section{Conclusion}

Both anatomic (CWT) and functional (endoFx) coronary changes can be detected using MRI before the development of stenotic disease and the functional abnormalities are related to the extent of local, early anatomic atherosclerosis (CWT). These findings demonstrate that even at the earliest stage of anatomic coronary atherosclerosis, endothelial-dependent functional changes are present and therefore, could contribute to the local progression of atherosclerosis.

\section{Author details}

'Johns Hopkins, Baltimore, MD, USA. ²Deutsches Herzzentrum Berlin, Berlin,

Germany. ${ }^{3}$ University of Lausanne, Lausanne, Switzerland.

Published: 2 February 2011

\section{References}

1. Hays AG, et al: JACC 2010, 9.

2. Fayad ZA, et al: Circulation 2000, 102:506-10.

3. Kim WY, et al: Circulation 2002, 106:296-9.

4. Botnar RM, et al: Circulation 2000, 102:2582-7.

doi:10.1186/1532-429X-13-S1-P242

Cite this article as: Hays et al:: Regional coronary endothelial function is related to local coronary wall thickness in CAD patients using 3T MRI.

Journal of Cardiovascular Magnetic Resonance 2011 13(Suppl 1):P242.

Submit your next manuscript to BioMed Central and take full advantage of:

- Convenient online submission

- Thorough peer review

- No space constraints or color figure charges

- Immediate publication on acceptance

- Inclusion in PubMed, CAS, Scopus and Google Scholar

- Research which is freely available for redistribution

Submit your manuscript at www.biomedcentral.com/submit 